\title{
Editorial
}

\section{Developmentally Appropriate Prevention of Aggression - Developmental Science as an Integrative Framework}

From a developmental science perspective, only an integrative framework has the potential to explain the development and function-prevention and intervention respectively-of aggressive behavior exhaustively considering findings from normal and abnormal development and complex biopsychosocial interactions. The present issue is thus rooted in a developmental science framework to extend the current research field on developmentally appropriate prevention and interventions for aggressive behavior in children and adolescents.

Developmentally appropriate preventions or interventions have the potential to modify human development. If an intervention has been successful in preventing aggression by modifying factors that were hypothesized to be causing the development of these problem behaviors, on the base of randomized controlled trials, then we have a test of that causal relationship (Tremblay \& Craig, 1995). Preventive interventions can thus modify the course of (mal)adaptive development thereby providing insight into the etiology and pathogenesis of aggression and antisocial behavior (Howe, Reiss, \& Yuh, 2002). Three different, but not incompatible approaches to the topic are important to distinguish:

The first approach is one that establishes relevant risk and protective factors as they encourage or mediate against aggression and antisocial behaviors (Rutter, Giller, \& Hagell, 1998). Usually, no single identified risk factor can be said to cause later problem aggressive behavior, and longitudinal studies have thus pointed to a range of overlapping risk and protective factors (Durlak, 1998). Second, developmental prevention and intervention is often conceptualized as "early in development," e.g., preschool "early prevention/intervention" can also refer to "early in the pathway" rather than early in life, as some pathways of aggressive behaviour have been identified to start in adolescence (Loeber \& Hay, 1997). Third, there are those who focus on developmental tasks for prevention purposes. By completing these tasks successfully, children acquire competencies that support them in their transition to master further developmental tasks.

Against this background, this issue assembles diverse perspectives on developmentally appropriate preventions and interventions for aggression and antisocial behavior in children and adolescents: The first article by Benson and Scales (2009) analyses the linkage of developmental assets on prevention of youth aggressive behaviors. They show that high levels of developmental assets are associated with lower levels of aggression and violence by providing young people with opportunities and skills needed for social integration.

Malti and Noam (2009) continue by providing a conceptual developmental framework to the prevention of adolescent's aggressive behavior and the promotion of resilience. The proposed model is rooted in social-cognitive theory and interconnects levels of adolescent development with concommitent vulnerabilities and strengths. 
The next article by Welsh and Farrington (2009) reviews the scientific evidence on the effectiveness of early developmental prevention programs at the individual and family levels, indicating that there is a number of effective early prevention programs designed to tackle the most important risk factors for offending.

Beelmann and Raabe (2009) tie in with their systematically review of the results of 26 reviews and meta-analyses on the effectiveness of antisocial behavior prevention programs. Although most interventions had significant positive effects on development (with low to moderate mean effect sizes), the authors also discuss limitations.

Finally, Masten, Long, I-Chun Kuo, McCormick, and Desjardins (2009) highlight the potential for a new era of developmentally informed interventions with a particular focus on the significance of developmental cascades and windows of opportunity for the prevention of antisocial behavior.

The following four articles summarize empirical findings on the basis of controlled trials of developmentally informed empirical intervention or prevention studies in different environments: The article by Jungmann, Ziert, Kurtz, and Brandt (2009) presents evaluation results from the German pilot project "Pro Kind", an adaptation of the US evidence-based Nurse-Family Partnership program to prevent early onset and later conduct problems. Kuschel, Heinrichs, and Hahlweg (2009) report the findings of a randomized controlled study to investigate the long-term efficacy of the Triple P parent group training. In the long term, the findings indicate small positive effect sizes for externalizing behavior. Klein, Gasteiger-Klicpera, and Schillinger (2009) longitudinally evaluate the effectiveness of a peer-mediation-program for $3^{\text {rd }}$ graders. Boys improved their prosocial behavior and decreased their direct and indirect aggression and victimisation, whereas the opposite effects were found for girls. Bull, Schultze, and Scheithauer (2009) present evaluation results of a school-based intervention program to prevent bullying and relational aggression in youth based on the "fairplayermanual". Bullying behavior and peer- and teacher-reported relational aggression decreased in the intervention group. The issue concludes with a commentary by Fuchs and Fooken (2009). The authors critically reflect upon the difficulties associated with conducting evidence-based evaluation studies in the German-speaking field of preventive practice.

In summary, the articles presented in this issue show that developmentally appropriate interventions or preventions should build on empirically and theoretically derived models of normal and abnormal developmental pathways, and on evidence about those factors that facilitate and promote child development, and those that hinder it, by (1) reducing the impact of important risk factors and fostering those factors that protect children from developing aggressive/antisocial behavior and enhance their resilience, (2) helping children to complete relevant developmental tasks, and (3) considering key developmental transitions and cultural circumstances in which children and adolescent grow up.

We are excited to present this work to you with the hope that it will inspire a great deal more significant theory, research and practice to reduce aggression and antisocial behavior and to increase developmental success in children and youth. There is no question that there is a tremendous amount of suffering in regards to aggression and antisocial 
behavior, that could be prevented if effective, integrative and just methods would be applied when symptoms appear or even better, when symptoms are suspected if nothing gets done at the appropriate time. This issue thus supports the advances that are possible within a developmental science framework and produces a starting point for the next phase of active research, practice and policy.

Tina Malti, Gil G. Noam, and Herbert Scheithauer

\section{References}

Beelmann, A., \& Raabe, T. (2009). The effects of preventing antisocial behavior and crime in childhood and adolescence: Results and implications of research reviews and meta-analyses. European Journal of Developmental Science, 3, 206-281.

Benson, P.L., \& Scales, P.C. (2009). Positive youth development and the prevention of youth aggression and violence. European Journal of Developmental Science, 3, 218-234.

Bull, H. D., Schultze, M., \& Scheithauer, H. (2009). School-based prevention of bullying and relational aggression: The fairplayer.manual. European Journal of Developmental Science, 3, 312-317.

Durlak, J. A. (1998). Common risk and protective factors in successful prevention programs. American Journal of Orthopsychiatry, 68, 512-520.

Fuchs, I., \& Fooken, I. (2009). Limitations of evidence-based practice for prevention programs "at practice" - Recollecting the experience with the family-based prevention program FAST in Germany. European Journal of Developmental Science, 3, 318-320.

Howe, G.W. Reiss, D., \& Yuh, J. (2002). Can prevention trials test theories of etiology? Development and Psychopathology, 14, 673-694.

Jungmann, T., Ziert, Y., Kurtz, V., \& Brand, T. (2009). Preventing adverse developmental outcomes and early onset conduct problems through prenatal and infancy home visitation: The German pilot project "Pro Kind”. European Journal of Developmental Science, 3, 292-298.

Klein, G., Gasteiger-Klicpera, B., \& Schillinger, M. (2009). Prevention of aggressive behaviour in elementary schools: Gender-related effects of a peer mediation program. European Journal of Developmental Science, 3, 304-311.

Kuschel, A., Heinrichs, N., \& Hahlweg, K. (2009). Is a preventive parenting program effective in reducing a child's externalizing behavior? European Journal of Developmental Science, 3, 299-303.

Loeber, R., \& Hay, D. (1997). Key issues in the development of aggression and violence from childhood to early adulthood. Annual Review in Psychology, 48, 371-410.

Malti, T., \& Noam, G.G. (2009). A developmental approach to the prevention of adolescent's aggressive behavior and the promotion of resilience. European Journal of Developmental Science, 3, 235-246.

Masten, A.S., Long, J.D., I-Chun Kuo, S., McCormick, C.M., \& Desjardins, C.D. (2009). Developmental models of strategic intervention. European Journal of Developmental Science, 3, 282-291.

Rutter, M., Giller, H, \& Hagell, A. (1998). Antisocial behavior by young people. Cambridge University Press: Cambridge.

Tremblay, R.E., \& Craig, W.M. (1995). Developmental crime prevention. Crime and Justice, 19, 151-236.

Welsh, B.C., \& Farrington, D.P. (2009). Early developmental prevention of delinquency and later offending: Prospects and challenges. European Journal of Developmental Science, 3, 247-259. 